\title{
Aide-mémoires in semantic dementia
}

\section{Sarah M Buchanan, Jonathan M Schott}

A 58 year-old right-handed woman developed progressive difficulty with naming. To help, she constructed and carried with her numerous pictures of items paired with their names (Figure 1). She subsequently developed prosopagnosia, personality change and an enhanced interested in religion. Examination revealed fluent speech, marked anomia, difficulties with word comprehension and surface dyslexic errors. Episodic memory and visuospatial skills were preserved. MR brain imaging (Figure 2) was consistent with semantic dementia [1]. Loss of word meaning is the cardinal feature of semantic dementia; there is some evidence that word training programmes may facilitate relearning of lost vocabulary [2].

References:

1. Warren JD, Rohrer JD, Rossor MN. Frontotemporal dementia. BMJ 2013;347:f4827

2. Savage SA, Ballard KJ, Piguet O, Hodges JR. Bringing words back to mind Improving word word production in semantic dementia. Cortex. 2013;49(7):18231832 


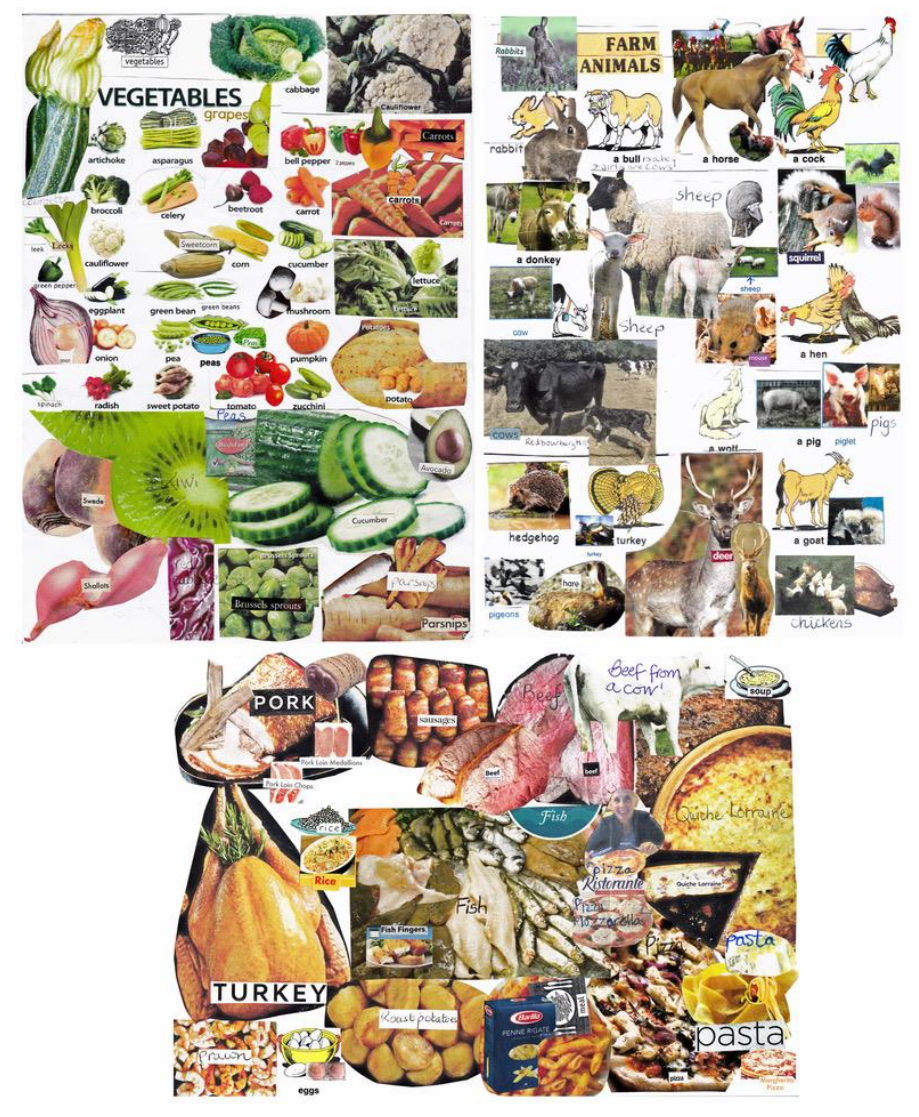

Figure 1. A selection of the patient's aide-memoires. She constructed dozens of sheets with pictures of items with their names associated, arranged by category. 


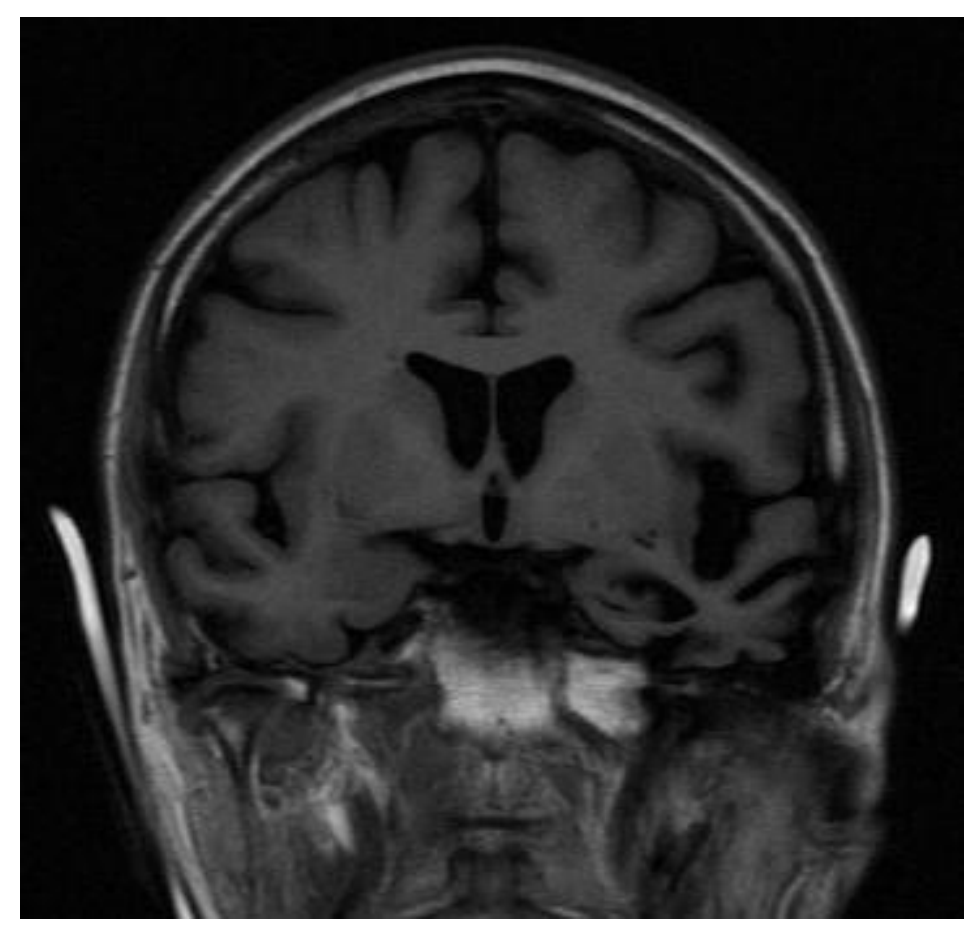

Figure 2. Coronal T1 weighted MRI shows asymmetric (left) temporal lobe atrophy with prominent inferior volume loss and relative preservation of the left superior temporal gyrus, in keeping with a diagnosis of semantic dementia 